Article

\title{
Controlling Particle Morphology and Pore Size in the Synthesis of Ordered Mesoporous Materials
}

\author{
Yaregal Awoke ${ }^{1,2}$, Yonas Chebude ${ }^{2}$ and Isabel Díaz 1,*(D) \\ 1 Instituto de Catálisis y Petroleoquímica, CSIC, C/Marie Curie 2, 28049 Madrid, Spain; \\ yaregal0918@yahoo.com \\ 2 Department of Chemistry, Arat Kilo Campus, Addis Ababa University, Addis Ababa 1230, Ethiopia; \\ yonasdb1@yahoo.com \\ * Correspondence: idiaz@icp.csic.es; Tel.: +34-915-854-785
}

Academic Editor: Yiyong Mai

Received: 30 September 2020; Accepted: 21 October 2020; Published: 23 October 2020

\begin{abstract}
Ordered mesoporous materials have attracted considerable attention due to their potential applications in catalysis, adsorption, and separation technologies, as well as biomedical applications. In the present manuscript, we aim at a rational design to obtain the desired surface functionality (Ti and/or hydrophobic groups) while obtaining short channels (short diffusion paths) and large pore size (>10 nm). Santa Barbara Amorphous material SBA-15 and periodic mesoporous organosilica PMO materials are synthesized using Pluronic PE 10400 (P104) surfactant under mild acidic conditions to obtain hexagonal platelet-like particles with very short mesochannels $(300-450 \mathrm{~nm})$. The use of expanders, such as 1, 3, 5-trimethylbenzene (TMB) and 1, 3, 5-triisopropylbenzene (TIPB) were tested in order to increase the pore size. TMB yielded in the formation of vesicles in all the syntheses attempted, whereas P104 combined with TIPB resulted both in expanded (E) E-SBA-15 and E-PMO with $12.3 \mathrm{~nm}$ pore size short channel particles in both cases. Furthermore, the synthesis method was expanded to the incorporation of small amount of Ti via co-condensation method using titanocene as titanium source. As a result, Ti-E-SBA-15 was obtained with $15.5 \mathrm{~nm}$ pore size and isolated Ti-sites maintaining platelet hexagonal morphology. Ti-PMO was obtained with $7.8 \mathrm{~nm}$ and short channels, although the pore size under the tried synthesis conditions could not be expanded further without losing the structural ordering.
\end{abstract}

Keywords: SBA-15; PMO; particle morphology; pore size; surface hydrophobicity

\section{Introduction}

The synthesis, characterization, and application of novel porous materials have been strongly encouraged due to their wide range of applications in adsorption, separation, catalysis, and biomedical field. Since the breakthrough achieved by the M41S family, reported by Mobil's researchers in 1992 [1], ordered mesoporous silica have attracted an extraordinary scientific interest in an interdisciplinary set of fields depending on the desired application. Due to the limited pore size of M41S materials, a new class of well-ordered mesoporous silica materials was synthesized at the University of California, being denoted as Santa Barbara Amorphous materials (SBA-15) in 1998 [2], which have relatively larger pore sizes and pore wall thicknesses as compared with the M41S family. SBA-15 materials are silica structures that present cylindrical pores of uniform diameter placed in hexagonal arrangement. Silicate mesoporous materials with high surface areas, combined with large and uniform pore sizes, have acquired great scientific interest in the use as hosts to support catalytic active sites [3] or to confine guest molecules, such as enzymes [4]. Periodic mesoporous organosilicas (PMO) with highly ordered pore structures and uniformly distributed organic groups inside of siliceous framework provided with a new range of surface chemistry in ordered mesoporous materials [5]. PMOs have been synthesized 
via the hydrolysis and condensation of bridged organosilsesquioxane species $\left((\mathrm{RO})_{3} \mathrm{Si}-\mathrm{R}-\mathrm{Si}(\mathrm{OR})_{3}\right)$ under basic or acidic conditions in the presence of various structure-directing agents [6].

Non-ionic surfactant Pluronic P123 $\left(\mathrm{EO}_{20} \mathrm{PO}_{70} \mathrm{EO}_{20}\right)$ is commonly used in the synthesis of SBA-15 and PMO. The resulting morphology in these syntheses is usually large fibers, in the orders of hundreds of microns. The lengthy channels and potential pore blockage along the channels are the main concerns when applying SBA-15 and PMO type ordered mesoporous materials in the sorption and catalysis of bulky molecules. The pore accessibility and molecular diffusion path in such types of materials can be improved by shortening the mesopore channel length [7] or enlarging the mesopore diameter [8].

In this study, new synthetic strategies were adopted to prepare SBA-15 and PMO with short channels, hexagonal platelet-like morphology, and large pore size ( $>10 \mathrm{~nm})$. This would improve the accessibility of the potential active sites and the diffusion and adsorption rate of the reactants and products [9]. Non-ionic Pluronic PE 10400 (P104, $\mathrm{EO}_{27} \mathrm{PO}_{61} \mathrm{EO}_{27}$ ) surfactant has been selected as structure-directing agent in order to control the particle morphology and textural properties [10]. The nature of the structure directing agent, the synthesis temperature, and the addition of other synthesis agents, such as inorganic salts and swelling agents, are key parameters that should be considered to control the properties of the final material. Inorganic salts improve the degree of ordering of PMO materials by the dehydration of the ethylene oxide (EO) units of the surfactant, which decreases their hydrophilicity and increases the hydrophobicity of the propylene oxide (PO) moieties. Thus, the interaction between the positively charged polyethylene oxide (PEO) groups and the relatively hydrophobic positively charged organosilane species is favored. The use of expanders is known in the conventional synthesis of SBA-15 with Pluronic P123 [11], although it has not been thoroughly tried with Pluronic PE 10400, with slightly more hydrophilic character that usually forms shorter micelles, which promotes SBA-15 growing preferentially in the $a b$ plane [12]. Furthermore, the use of Pluronic PE 10400 has not been attempted to prepare PMO with hexagonal platelet-like morphology let alone, to prepare expanded pore-PMO materials.

In this work, we introduce the morphology control using Pluronic P104 to the synthesis of PMO, and develop a method to obtain large pore, or expanded, E-SBA-15 and E-PMO in the synthesis conditions that produce hexagonal platelet-like morphology. Furthermore, in the course of our work to produce short diffusion paths in catalysis, we extended to a facile method to synthesize platelet-like Ti-SBA-15 and Ti-PMO particles with good textural properties and short channel cylindrical mesopores in the presence of small amount of titanocene dichloride. Based on early reports on the use of titanocene as the optimum source for the incorporation of isolated active oxidative sites [13], we expanded the synthetic approach to the use of Pluronic PE 10400 and expanders, such as TIPB obtaining, expanded Ti-surface modified SBA-15 and PMO.

\section{Results}

\subsection{Characterization of SBA-15 and Ti-SBA-15 Ordered Mesoporous Materials}

The obtained samples were characterized by low angle powder X-ray diffraction to evaluate the pore arrangement, scanning and transmission electron microscopy to evaluate the morphology and internal structure of the particles, and $\mathrm{N}_{2}$ adsorption/desorption isotherm, to obtain the textural properties of the supports.

Figure 1a shows the low angle X-ray diffraction patterns for the materials prepared with Pluronic P104, labeled with "S" as short, SBA-S and Ti-SBA-S, aiming at short channels. Both SBA-S and Ti-SBA-S materials show a typical XRD pattern of an ordered hexagonal network arrangement of mesopores. The presence of one very intense diffraction peak, $d_{100}$, and two weak peaks $d_{110}$ and $d_{200}$ in both materials characterize a well-defined 2D hexagonal symmetry mesoporous structure belonging to the $p 6 m m$ space group. 


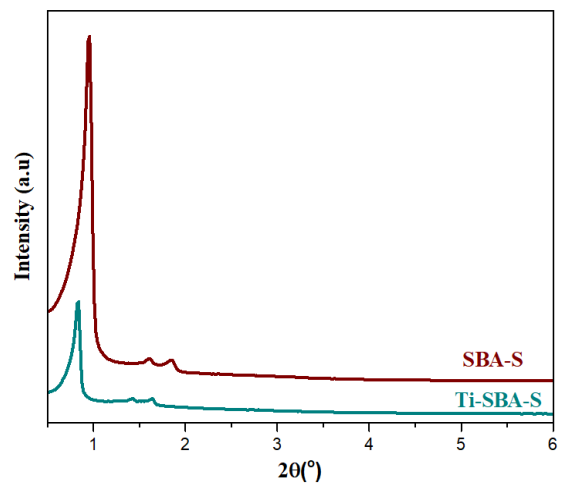

(a)

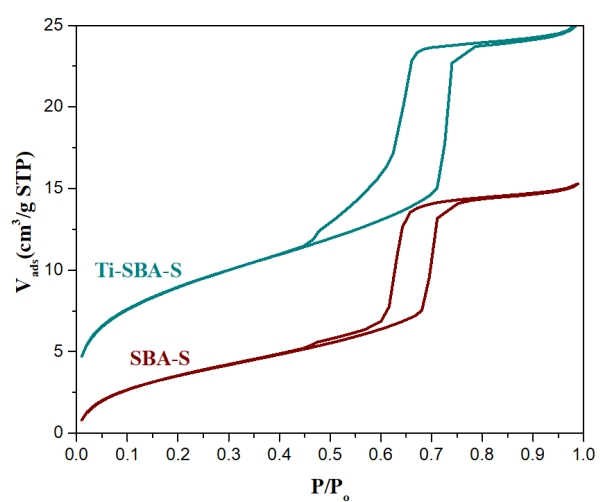

(b)

Figure 1. (a) Low angle XRD pattern; (b) $\mathrm{N}_{2}$ adsorption-desorption isotherms of "short" SBA-15 materials SBA-S and Ti-SBA-S.

Interestingly, the incorporation of small amount of titanocene does not alter the formation of a highly ordered hexagonal structure. Ti-SBA-S is obtained with $5 \%$ of titanocene in the synthesis gel provoking the co-condensation of Ti-cyclopentadienyl (Cp) species to condense with the silicate at the pore surface. As a result, this sample shows slightly larger unit cell $(12.1 \mathrm{~nm})$ than the pure silica $(10.6 \mathrm{~nm})$ (Figure 1a and Table 1). This larger unit cell parameter may be indicating that there is an efficient interaction of cyclopentadienyl with the core of the micelle causing the pore size and unit cell dimension increment. The $\mathrm{N}_{2}$ adsorption-desorption isotherms of calcined SBA-S and Ti-SBA-S materials are shown in Figure $1 \mathrm{~b}$ and their textural properties are summarized in Table 1. The adsorption/desorption isotherm of both materials exhibit the classic type IV adsorption isotherms, according to the IUPAC classification [14], with an H1-type hysteresis loop, which is characteristic of mesoporous materials with uniformly distributed cylindrical channels. The adsorption and desorption branches are located at high relative pressure $\left(\mathrm{P} / \mathrm{P}_{\mathrm{o}}\right.$ between $\left.0.5-0.8\right)$ characteristic of mesoporous materials. The adsorption branch of Ti-SBA-S material is shifted slightly toward higher $\mathrm{P} / \mathrm{P}_{\mathrm{o}}$, which suggests an increase of the pore size. This pore size difference is also confirmed by DFT (Density functional theory) calculations, the pore size of SBA-S and Ti-SBA-S materials are 9 and $10 \mathrm{~nm}$, respectively. The pore size, surface area and pore volume of Ti-SBA-S material is slightly higher than the SBA-S material.

Table 1. Structural parameters of SBA-15 and periodic mesoporous organosilicas (PMO) samples.

\begin{tabular}{ccccc}
\hline Sample & $\mathbf{a}_{\mathbf{o}}(\mathbf{n m})$ & $\mathbf{S}_{\text {BET }}\left(\mathbf{m}^{\mathbf{2}} \mathbf{g}^{\mathbf{- 1}}\right)$ & $\mathbf{V}\left(\mathbf{c m}^{\mathbf{3}} \mathbf{g}^{-\mathbf{1}}\right)$ & $\mathbf{D}_{\text {DFT }}(\mathbf{n m})$ \\
\hline SBA-S & 10.6 & 579 & 0.65 & 9 \\
Ti-SBA-S & 12.1 & 896 & 0.93 & 10.1 \\
E-SBA-S & 13.7 & 701 & 0.76 & 12.3 \\
Ti-E-SBA-S & 16.2 & 822 & 1.17 & 15.5 \\
PMO-S & 11.6 & 672 & 0.57 & 7.1 \\
Ti-PMO-S & 12 & 706 & 0.59 & 7.8 \\
E-PMO-S & 15.9 & 843 & 0.86 & 12.3 \\
\hline
\end{tabular}

The particle morphology of both SBA-S and Ti-SBA-S materials was characterized by scanning electron microscopy (SEM) to confirm whether our objective has been achieved or not. SBA-S material is composed of platelet particles, with diameters of $3.2 \mu \mathrm{m}$, while the materials synthesized in the presence of titanocene dichloride, Ti-SBA-S, have hexagonal platelets-like particle morphology with diameter of $2 \mu \mathrm{m}$ (Figure 2). Although both materials have short channels and plates-like particle morphology, hexagonal particles with smaller diameter is shown in the Ti-SBA-S material. This different growth rate may be related to the milder acidic conditions employed in the Ti-synthesis, although it could also be due to the delay in the initial condensations step due to the presence of titanocene dichloride. 


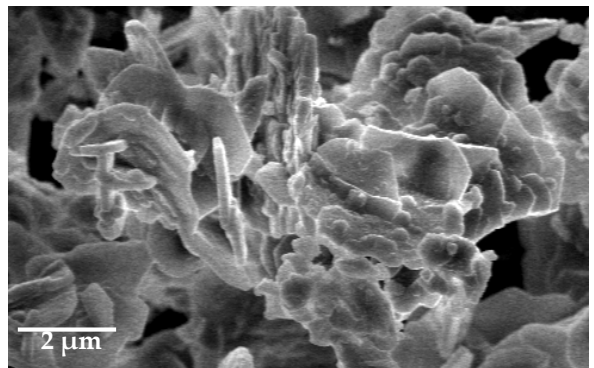

(a)

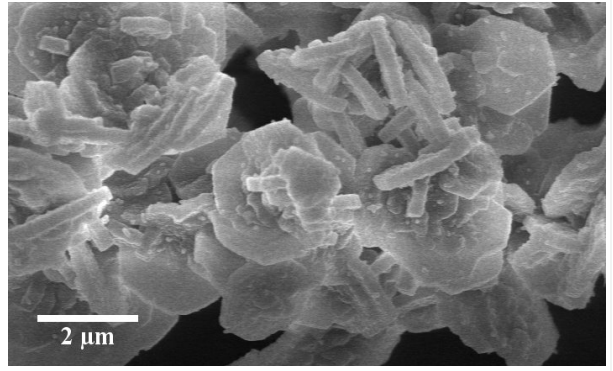

(b)

Figure 2. Scanning electron microscopy micrographs of: (a) SBA-S; (b) Ti-SBA-S materials.

In order to facilitate the adsorption and diffusion rate of bulky molecules, we tried to prepare materials with larger pore diameter than the standard pore size materials. Several experimental methods were attempted, only the most relevant ones are highlighted here. Initially, we tried to expand the pore size of SBA-S using 1,3,5-trimethylbenzene (TMB) as a pore expander (sample code M-SBA-S). Figure 3a shows the low angle $X$-ray diffraction patterns for the synthesized mesoporous silica materials with pore expanders. All XRD peaks of M-SBA-S disappear, suggesting that the addition of (TMB) leads to the loss of the hexagonal arrangement of pores. This may be due to uncontrolled interaction with the triblock copolymers that causes disruption of the micellar phase of P104 producing less ordered mesocellular foam material with a wider pore size [15]. TEM image in the inset of Figure 3a corroborates the ringed multi-lamellar silica vesicles with no open pores and no hexagonal arrangements. This result is less pronounced when using P123, yet it has been discussed in the literature as a result of the pore expansion $[16,17]$. Therefore, we tried to expand the pore size of both types of materials by using another type of pore expander, 1, 3, 5-triisopropylbenzene (TIPB), which has relatively large size and more hydrophobic group. This characteristic may help the expander to selectively interact with the core of the micelle. Figure 3a shows the low angle X-ray diffraction patterns for the synthesized expanded SBA-15 materials (labeled with "E") for both silica E-SBA-S and with a small amount of titanocene in the synthesis gel, Ti-E-SBA-S. It can be observed that both E-SBA-S and Ti-E-SBA-S materials exhibit XRD patterns with one very intense diffraction peak (100), and two weak peaks (110) and (200), which are characteristic of 2-dimensional hexagonal p6mm structure with excellent uniformity. The XRD peaks of both materials were shifted towards lower $2 \theta$ value (larger $\mathrm{a}_{\mathrm{o}}$, see Table 1 ) when compared to their SBA-S and Ti-SBA-S parent materials. This confirms that TIPB increases the unit cell dimension without affecting the pore arrangement of the material. These materials were further characterized by $\mathrm{N}_{2}$ adsorption-desorption isotherm in order to confirm the pore size difference with the parent material.

The $\mathrm{N}_{2}$ adsorption-desorption isotherms of the calcined E-SBA-S and Ti-E-SBA-S materials are given in Figure $3 \mathrm{~b}$ and their textural properties are summarized in Table 1. Both materials exhibit the classic type IV adsorption isotherms, with an H1-type hysteresis loop which is characteristic of mesoporous materials with cylindrical channels. The adsorption and desorption branches of these materials are located at higher relative pressure and the hysteresis loop shifted slightly towards higher relative pressure $\left(P / P_{o}=0.9\right)$ when compared to their parent ones, which suggests an increase of the pore size. However, the presence of two distinctive steps in the desorption branch of the isotherm may indicate the presence of partial blockage of some mesopores or presence of bottlenecks. The pore size obtained from the adsorption branch using DFT cylindrical model yields successfully larger pore sizes in both cases, as large as $12.3 \mathrm{~nm}$ for pure silica sample and $15.5 \mathrm{~nm}$ for the Ti-modified SBA-15 materials, which are rather large compared to those reported in the literature, at least for Ti-SBA-15 [18]. 


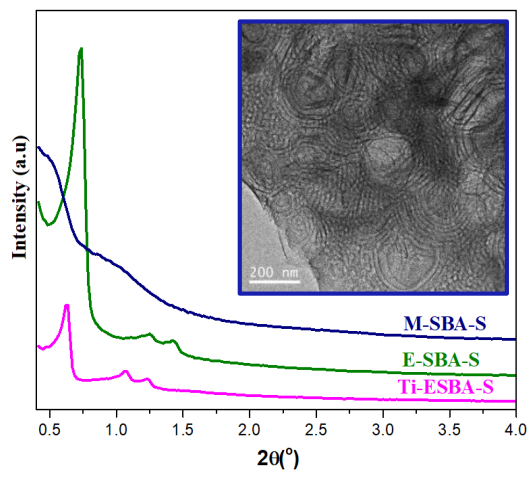

(a)

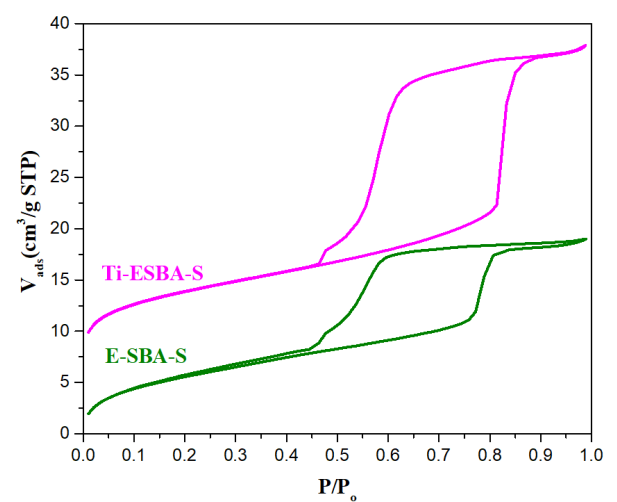

(b)

Figure 3. (a) Low angle XRD patterns of expanded samples: M-SBA-S using TMB, and E-SBA-S and Ti-E-SBA-S using TIPB. Inset corresponds to the TEM image of M-SBA-S showing vesicles; (b) $\mathrm{N}_{2}$ adsorption-desorption isotherms of E-SBA-S and Ti-E-SBA-S materials.

In order to understand the presence of this small second step, these samples were further studied by TEM. Figure 4 shows the TEM images of both E-SBA-S and Ti-E-SBA-S depicting the well-ordered mesoporous structures in both materials. The presence of very thick layers surrounding the outer surface of the particles in E-SBA-S may explain the presence of partially blocked pore mouths (lack of pore openings); however, no blockage was observed in Ti-E-SBA-S material, where the channels and the pore mouths are accessible [9].

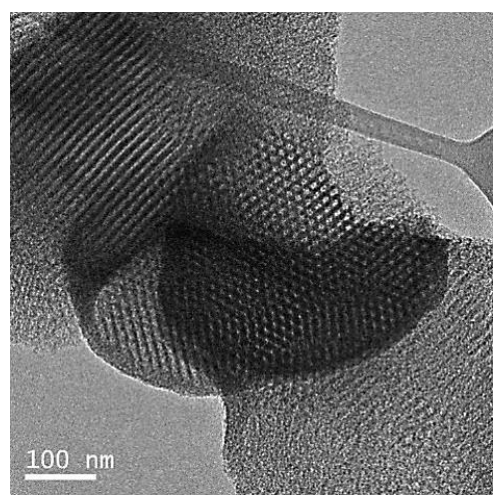

(a)

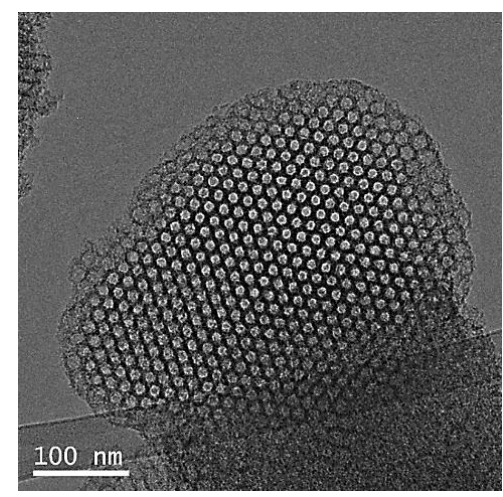

(b)

Figure 4. TEM images of: (a) E-SBA-S and (b) Ti-E-SBA-S materials.

The particle morphology of both E-SBA-S and Ti-E-SBA-S materials were analyzed by SEM (Figure 5). E-SBA-S seems to form fibers but the fibers being formed by aggregates Figure $5 \mathrm{a}$. The particle morphology of E-SBA-S is affected by the addition of the TIPB expander probably due to the different particle growth mechanism when compared with the parent SBA-S material. In the Ti-E-SBA-S material discrete particles are formed, attached short end to short end Figure $5 b$. When the synthesis is conducted in the presence of expander, the size of the crystals is much smaller, $0.5 \mu \mathrm{m}$ particle diameter, having the shape of small cylinders. 


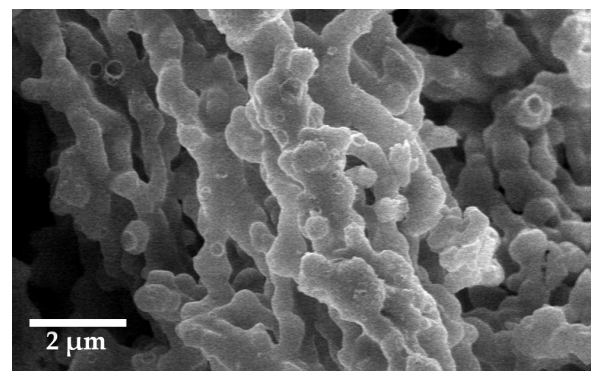

(a)

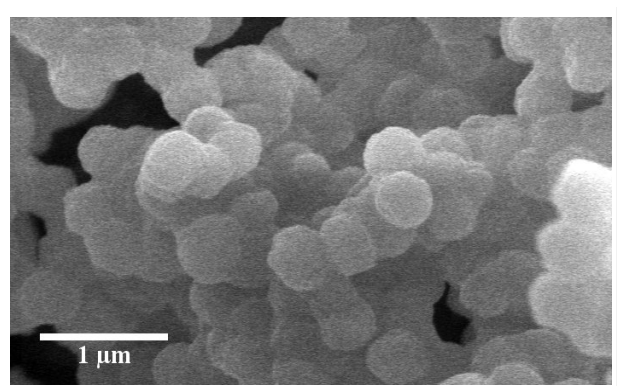

(b)

Figure 5. Scanning electron microscopy micrographs of: (a) E-SBA-S; (b) Ti-E-SBA-S materials.

\subsection{Characterization of PMO and Ti-PMO Hybrid Ordered Mesoporous Materials}

In order to tune the adsorption capacity and rate of diffusion of organic reagents the synthesis of materials with hydrophobic group, periodic mesoporous organosilica, with short particle morphology and large pore size was aimed. The synthesis condition of PMOs is carried out at mild acidic conditions. Figure 6a shows the low angle X-ray diffraction patterns of PMO-S and Ti-PMO-S materials. The presence of one very intense peak (100) and two weak peaks (110) and (200) in both materials indicates that both are ordered materials with the hexagonal arrangement of mesopores belonging to p6mm symmetry. The presence of small amount of titanocene in the synthesis gel does not seem to alter the structure directing effect of P104 surfactant even when the silica source is a bridged one. Ti-PMO-S material has slightly larger unit cell dimensions than PMO, 12 and $11.6 \mathrm{~nm}$, respectively (see Table 1).

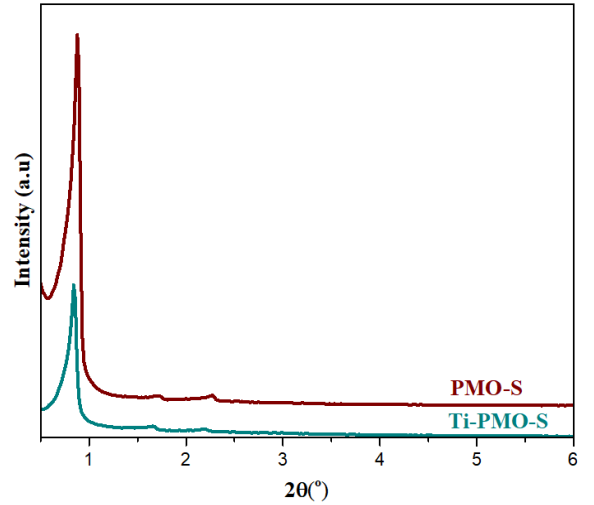

(a)

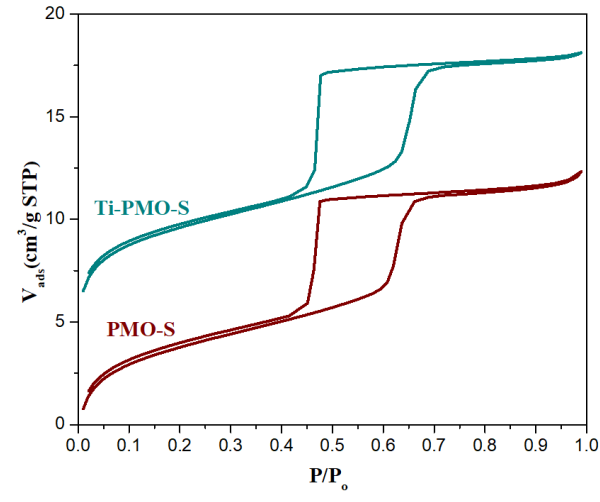

(b)

Figure 6. (a) Low angle XRD patterns; (b) $\mathrm{N}_{2}$ adsorption-desorption isotherms of PMO-S and Ti-PMO-S materials.

These materials were characterized by $\mathrm{N}_{2}$ adsorption/desorption isotherms to compare their textural properties. Figure $6 \mathrm{~b}$ shows $\mathrm{N}_{2}$ isotherms for the calcined hybrid organosilica materials. The isotherms of both materials are type IV, with $\mathrm{H} 1$ type hysteresis loop at high relative pressure, which is characteristic of mesoporous materials with uniform size cylindrical pores. The DFT pore size is the same in both materials, close to $8 \mathrm{~nm}$, which is relatively larger when compared with the pore size of Ti-PMO material reported in the literature, which is close to $6 \mathrm{~nm}$, [19]. The desired effect of morphology modification was observed by scanning electron microscopy. SEM images of PMO-S and Ti-PMO-S are shown in Figure 7, showing platelets morphology with short channels. Therefore, from SEM, we can conclude that the particle morphologies of PMO materials can be controlled by using Pluronic P104 as a surfactant, and particle dimension of $3.2 \mu \mathrm{m}$ diameter by $550 \mathrm{~nm}$ length is obtained. This channel dimension is roughly similar with the SBA-S material, which has been synthesized by using the same type of surfactant but different type of silica source. 


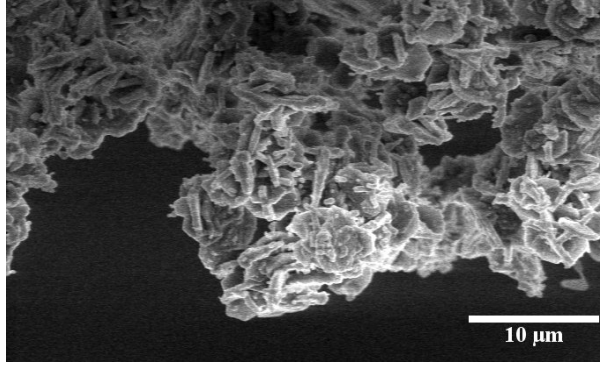

(a)

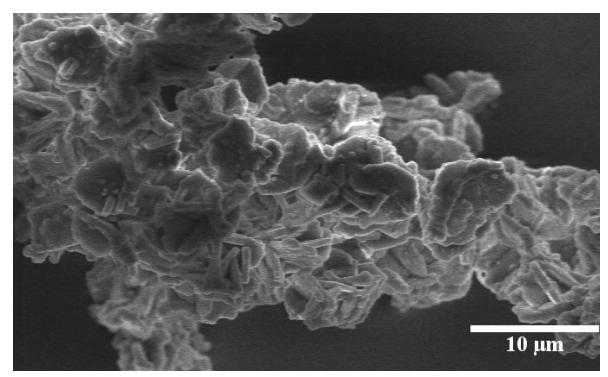

(b)

Figure 7. Scanning electron micrographs of: (a) PMO-S; (b) Ti-PMO-S materials.

Different attempts were made to synthesize large pore size PMO materials using 1,3,5-trimethylbenzene (TMB) as a pore expander (M-PMO-S). However, all the XRD peaks disappear indicating that the M-PMO-S material completely loses its structure due to the effect of TMB similarly as M-SBA-S sample. Thus, we tried to expand the pore size of the PMO materials using TIPB as a pore expander. Figure 8a shows the low angle X-ray diffraction patterns for an expanded E-PMO material prepared with TIPB using P104 as surfactant. The presence of one strong peak (100) and two less resolved peaks (110) and (200) of E-PMO-S corroborates that the structure is less ordered, yet the main peak in this material is shifted towards the lower $2 \theta$, which indicates that the unit cell dimension increases due to the effect of the micelle expander.

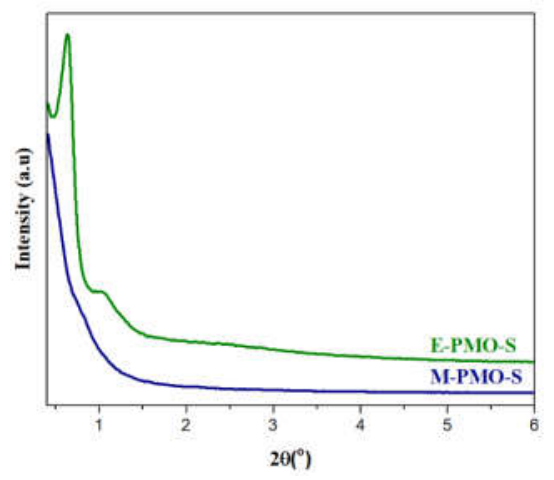

(a)

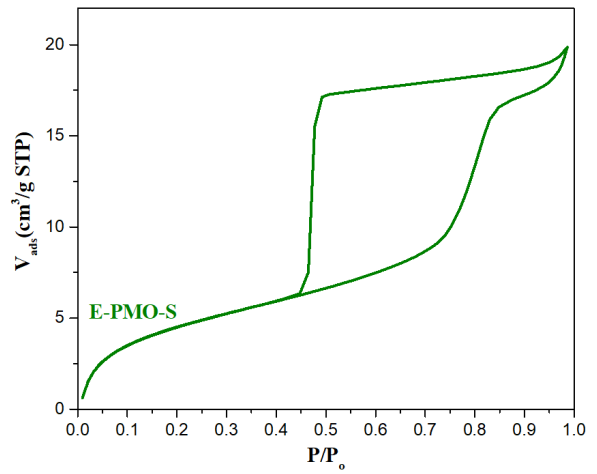

(b)

Figure 8. (a) Low angle XRD patterns; (b) $\mathrm{N}_{2}$ adsorption-desorption isotherm of E-PMO-S.

Figure $8 \mathrm{~b}$ shows the $\mathrm{N}_{2}$ adsorption-desorption isotherm for E-PMO-S material and the textural properties are given in Table 1. The isotherm obtained in E-PMO-S sample is type IV isotherm with $\mathrm{H} 1$ type hysteresis loop indicating uniform pore size distribution. However, the adsorption branch of the isotherm is not as sharp as it should be for a highly ordered OMM, probably due to the presence of bottlenecks causing delays in the diffusion of the gas. Nevertheless, the pore size according to DFT calculations has successfully been expanded to $12.3 \mathrm{~nm}$, more than $5 \mathrm{~nm}$ larger than the parent material PMO-S $(7.1 \mathrm{~nm})$. TEM observations confirmed that the mesoporous structure in this material is indeed not hexagonally packed, rather, it is formed by disordered arrangement with wormlike mesochannels [20]. The particle morphology of E-PMO-S material is given in Figure 9b, showing agglomerates of shapeless small particles. 


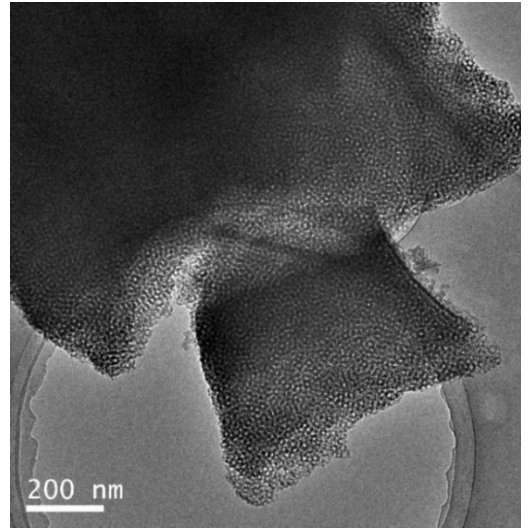

(a)

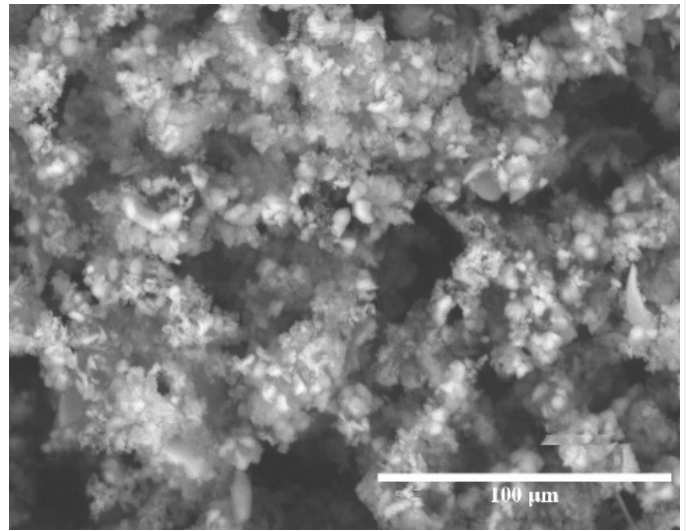

(b)

Figure 9. Structure and morphology of large pore size E-PMO-S material (a) TEM and (b) SEM images.

\section{Discussion}

SBA-15 and PMO materials are synthesized using nonionic surfactant Pluronic PE104 which has the general formula $\mathrm{EO}_{27} \mathrm{PO}_{61} \mathrm{EO}_{27}$. Polyethylene oxide (PEO) sections of the surfactant are hydrophilic and responsible for the interaction with the silica source. In acidic media, PEO becomes highly depolymerized and protonated interacting by H-bonds with the protonated silica source. On the other hand, polypropylene oxide (PPO) units are responsible for the hydrophobic core of the micelles. The presence of equivalent amount of hydrophilic PEO and hydrophobic PPO group in the surfactant molecule may assist the formation of short channel and platelet-like particle morphology. This may be due to the side to side interaction among the particles during crystal growth. This fact is clearly supported by Linton et al. [7], which clearly shows the growth mechanism of the particles with plate-like hexagonal prisms morphology by using Pluronic P104 surfactant at high synthesis temperature $\left(50-65^{\circ} \mathrm{C}\right)$ and relatively concentrated acidic condition $(1.6 \mathrm{M})$. Here, we add titanocene dichloride into the synthesis gel at milder acidic condition, and swelling agents, such as TIPB, at lower synthesis temperature.

In this synthesis approach, titanocene dichloride $\left(\mathrm{Cp}_{2} \mathrm{TiCl}_{2}\right)$ was added before the addition of silica source, during the SBA-15 and PMO synthesis, respectively. In this method of synthesis Ti (IV) ion was incorporated, while maintaining degree of ordering of the material and its particle morphology. The presence of small amount of cyclopentadienyl groups, may facilitate the aggregation of smaller units (primary particles) in the oriented manner, during the formation of ordered mesoporous materials. As compared to their corresponding parent materials, Ti incorporated materials have higher unit cell dimension, larger textural properties (surface area, pore volume, pore diameter and pore wall thickness), perhaps induced by the species from the titanium precursor utilized in the synthesis. Besides, the materials synthesized in the presence of titanocene dichloride Ti-SBA-S and Ti-PMO show a smaller particle size, contributing to the aforementioned better textural properties. This morphological difference may be due to the increase of particle-particle attraction upon the addition of $\mathrm{Cp}_{2} \mathrm{TiCl}_{2}$. This was explained by Linton et al. [12], where the aggregation of primary particles was promoted by adding inorganic salts ( $\mathrm{NaCl}$ and $\mathrm{NaI})$. Perhaps, in this case, this is due to the effect of both the cation and the anion species present in the synthesis gel.

Ti-E-SBA-S has large pore size and cylindrical shaped particle morphology with diameter $0.5 \mu \mathrm{m}$. This result also indicates that the presence of pore expanders in the synthesis gel may facilitate nucleation and hinders particle growth yielding the decrease of the particle. This fact was also observed by Johansson et al. [21] in the synthesis of SBA-15 in the presence of heptane.

In the case of the synthesis of PMO, Pluronic P104 is used here for the first time instead of the more frequently used Pluronic P123 [22], obtaining PMO materials with platelet particle morphology. PMO-S and Ti-PMO-S have similar particle size and pore wall thickness. However, Ti-PMO-S material 
has slightly higher pore diameter, surface area and pore volume may be due to the modulation of the acidity, or presence of small amount of titanocene dichloride in the synthesis gel that may improve the orientation of the particles [23]. The presence of expander has led to the loss of hexagonal order and, thus, the platelet-like particle morphology.

\section{Materials and Methods}

\subsection{Materials}

Pluronic P104 $\left(\mathrm{PEO}_{27} \mathrm{PPO}_{62} \mathrm{PEO}_{27}\right)$ BASF, USA, was used as a structure directing agent. Tetramethoxysilane (TMOS) Alfa Aesar, Germany, ammonium fluoride $\left(\mathrm{NH}_{4} \mathrm{~F}\right), 1$, 3, 5-triisopropylbenzene (TIPB), 1, 3, 5-trimethylbenzene (TMB) Alfa Aesar (Germany), 1,2-bis(trimethoxysilyl)ethane (BTMSE, 96\%, Sigma Aldrich, St. Louis, MO, USA), and 1,2-bis-(triethoxysilyl)ethane (BTESE, 97\%, Merck, NJ, USA were used as a source of silicon and ethane group for PMO synthesis, and titanocene dichloride $\left(\mathrm{Cp}_{2} \mathrm{TiCl}_{2}\right)$ (Sigma- Aldrich, St. Louis, MO, USA).

\subsection{Synthesis of SBA-15 and Ti-SBA-15}

Pure silica SBA-15 was synthesized using Pluronic PE $10400\left(\mathrm{P} 104,(\mathrm{EO})_{27}(\mathrm{PO})_{61}(\mathrm{EO})_{27}\right)$ as a structure directing agent and with tetramethyl orthosilicate (TMOS) as the silica source. Pluronic P104 $(2.5 \mathrm{~g}, 0.423 \mathrm{mmol}$ ) was dissolved in $1.6 \mathrm{M}$ aqueous $\mathrm{HCl}$ solution $(97.5 \mathrm{~g})$. The mixture was stirred at room temperature in a closed Pyrex container until a homogenous clear solution was obtained. Then, the solution was heated at $55{ }^{\circ} \mathrm{C}$ for $1 \mathrm{~h}$ to homogenize the temperature. TMOS (3.69 mL, $24.79 \mathrm{mmol}$ ) was then added to the solution and the resulting mixture was vigorously stirred at $55^{\circ} \mathrm{C}$ for $24 \mathrm{~h}$. The final molar composition of the synthesis gel was 1 TMOS: 0.017 P104: $5.25 \mathrm{HCl}: 206 \mathrm{H}_{2} \mathrm{O}$. Subsequently, the container was transferred to an oven and kept at $80^{\circ} \mathrm{C}$ for $24 \mathrm{~h}$ under static conditions. The resultant product was filtered, washed thoroughly with absolute ethanol and air-dried at room temperature overnight. Finally, the surfactant template was removed by calcination at $550{ }^{\circ} \mathrm{C}$ for $5 \mathrm{~h}$ in air (heating ramp rate: $2{ }^{\circ} \mathrm{C} / \mathrm{min}$ ). This material was labeled as SBA-S as in "short".

The particle morphology of this short channel material was further controlled by adding small amount of titanocene dichloride and ammonium fluoride in the synthesis gel under mild acidic conditions. The final molar composition of the synthesis gel was 1 TMOS: 0.015 P104: $0.05 \mathrm{Cp}_{2} \mathrm{TiCl}_{2}$ : $0.03 \mathrm{NH}_{4} \mathrm{~F}: 0.33 \mathrm{HCl}: 188 \mathrm{H}_{2} \mathrm{O}$. Subsequently, the container was transferred to an oven and kept at $60{ }^{\circ} \mathrm{C}$ for $48 \mathrm{~h}$ under static conditions. This material was labeled as Ti-SBA-S.

To produce expanded pore E-SBA-S, Pluronic PE104 $(1.55 \mathrm{~g}(0.263 \mathrm{mmol}))$ and $\mathrm{NH}_{4} \mathrm{~F}(0.016 \mathrm{~g}$ $(0.432 \mathrm{mmol})$ ) were dissolved in $65.0 \mathrm{~mL}$ of $1.1 \mathrm{M}$ aqueous $\mathrm{HCl}$ solution at room temperature in a closed Pyrex container with stirring. Then, the micelle expander TIPB (0.8 mL (3.3 mmol)) or TMB $(0.46 \mathrm{~mL}$ ( $3.3 \mathrm{mmol})$ ) was added and mixed for $0.5 \mathrm{~h}$, and the calculated amount of TMOS (2.2 $\mathrm{mL}$ $(14.78 \mathrm{mmol})$ ) was added in under vigorous stirring. The final molar composition of the synthesis gel was 1 TMOS: 0.017 P104: 0.2 TIPB: $0.03 \mathrm{NH}_{4} \mathrm{~F}: 4.84 \mathrm{HCl}: 236 \mathrm{H}_{2} \mathrm{O}$. The white gel obtained was vigorously stirred for $24 \mathrm{~h}$ at $15{ }^{\circ} \mathrm{C}$ and subsequently heated at $80{ }^{\circ} \mathrm{C}$ in the closed container under static conditions for $48 \mathrm{~h}$. The mixture was then filtered, and the solid product was washed with absolute ethanol and dried at room temperature. Finally, the sample was calcined in a furnace for $5 \mathrm{~h}$ at $550{ }^{\circ} \mathrm{C}$ (heating ramp rate: $2{ }^{\circ} \mathrm{C} / \mathrm{min}$ ). This material was labeled as E-SBA-S.

The same synthesis method with the addition of small amount of titanocene dichloride in the synthesis gel with the molar composition: 1 TMOS: $0.05 \mathrm{Cp}_{2} \mathrm{TiCl}_{2}$ : 0.018 P104: 0.22 TIPB: 0.03 NH $\mathrm{N}_{4}$ : $5 \mathrm{HCl}: 250 \mathrm{H}_{2} \mathrm{O}$ was labeled as Ti-E-SBA-S.

\subsection{Synthesis of PMO and Ti-PMO}

Ethylene-bridged periodic mesoporous organosilica (PMO) with short channels and platelets-like particle morphology was as follows: Pluronic P104 (3.25 g (0.55 mmol)) was dissolved at room temperature in $126.84 \mathrm{~mL}$ of $0.174 \mathrm{M} \mathrm{HCl}$ aqueous solution in a flask with slow stirring. Once the 
surfactant was dissolved, potassium chloride $(9.38 \mathrm{~g}, 125.8 \mathrm{mmol})$ was added and dissolved in the solution. When the resulting solution was homogenized, it was heated to a constant temperature of $40{ }^{\circ} \mathrm{C}$. Then, 1, 2-bis (triethoxysilyl) ethane $(5.83 \mathrm{~mL}(15.75 \mathrm{mmol})$ ) was added at once with rapid stirring. The final molar composition of the synthesis gel was 1 BTESE: 0.035 P104: $8 \mathrm{KCl}: 1.39 \mathrm{HCl}$ : $445 \mathrm{H}_{2} \mathrm{O}$. The resulting mixture was stirred at $40{ }^{\circ} \mathrm{C}$ for $24 \mathrm{~h}$ and then aged at $80{ }^{\circ} \mathrm{C}$ under static conditions for $24 \mathrm{~h}$. The solid product was recovered by filtration, washed with ethanol and dried at room temperature for $24 \mathrm{~h}$. Finally, the sample was calcined for $5 \mathrm{~h}$ at $350{ }^{\circ} \mathrm{C}$ (heating ramp rate: $2{ }^{\circ} \mathrm{C} / \mathrm{min}$ ) and this material was labeled as PMO-S.

The particle morphology and textural properties of this short channel PMO material was further controlled by adding small amount of titanocene dichloride and ammonium fluoride in the synthesis gel under mild acidic conditions. The final molar composition of the synthesis gel was 1 BTESE: 0.033 P104: $0.02 \mathrm{Cp}_{2} \mathrm{TiCl}_{2}: 8 \mathrm{KCl}: 0.03 \mathrm{NH}_{4} \mathrm{~F}: 1.07 \mathrm{HCl}: 492 \mathrm{H}_{2} \mathrm{O}$. Then, the resultant mixture was stirred at $40{ }^{\circ} \mathrm{C}$ for $24 \mathrm{~h}$ and hydrothermally aged in the oven at $80^{\circ} \mathrm{C}$ under static conditions for $24 \mathrm{~h}$. The solid product was recovered by filtration, washed with ethanol and air-dried overnight. Finally, the surfactant was removed by calcination at $350{ }^{\circ} \mathrm{C}$ for $5 \mathrm{~h}$ in air (heating ramp rate: $2{ }^{\circ} \mathrm{C} / \mathrm{min}$ ). This material was labeled as Ti-PMO-S.

Pluronic P104 $(1.95 \mathrm{~g}(0.33 \mathrm{mmol}))$ and $\mathrm{NH}_{4} \mathrm{~F}(0.01 \mathrm{~g}(0.27 \mathrm{mmol}))$ were dissolved at room temperature in $85.24 \mathrm{~mL}$ of $0.12 \mathrm{M}$ aqueous $\mathrm{HCl}$ solution in a flask with slow stirring. Once the surfactant was dissolved, $\mathrm{KCl}$ (5.63 $\mathrm{g}(75.52 \mathrm{mmol})$ was added. When the resulting solution was homogenized, it was transferred into an incubator to a constant temperature of $15^{\circ} \mathrm{C}$. Then, $\operatorname{TIPB}(0.96 \mathrm{~mL}(3.96 \mathrm{mmol}))$ was added and stirred for $0.5 \mathrm{~h}$ before adding 1,2-bis(trimethoxysilyl)ethane ( $2.36 \mathrm{~mL}(9.36 \mathrm{mmol})$ ). The final molar composition of the synthesis gel was 1 BTMSE: 0.035 P104: 0.4 TIPB: $8 \mathrm{KCl}: 0.03 \mathrm{NH}_{4} \mathrm{~F}$ : $1.09 \mathrm{HCl}: 504 \mathrm{H}_{2} \mathrm{O}$. The resulting mixture was stirred at $15^{\circ} \mathrm{C}$ for $24 \mathrm{~h}$ and then aged at $80^{\circ} \mathrm{C}$ under static conditions for $48 \mathrm{~h}$. The solid product was recovered by filtration, washed with ethanol, and dried at room temperature. The surfactant was removed by calcination in a furnace for $5 \mathrm{~h}$ at $350{ }^{\circ} \mathrm{C}$ (heating ramp rate: $2^{\circ} \mathrm{C} / \mathrm{min}$ ) and this material was labeled as E-PMO-S.

\subsection{Characterization Techniques}

X-ray Diffraction (XRD) Patterns of the samples were obtained with a Philips X'PERT diffractometer using $\mathrm{Cu} \mathrm{K} \alpha$ radiation. Nitrogen adsorption-desorption isotherms were measured at $-196{ }^{\circ} \mathrm{C}$ using the micrometrics ASAP 2420 sorptometer to determine textural properties. All samples were degassed at $350{ }^{\circ} \mathrm{C}$ for $16 \mathrm{~h}$. The total pore volume was determined from the amount of nitrogen adsorbed at a relative pressure of 0.97 . Pore size distributions were determined from the adsorption branches of isotherms using the DFT model with cylindrical geometry of the pores. Transmission electron microscopy (TEM) micrographs were taken using a JEOL 2100F electron microscope operating at $200 \mathrm{kV}$. The samples for TEM analysis were prepared by suspending a small amount of solid in ethanol. A drop of this suspension was then dispersed onto a holey carbon film on a copper grid, followed by drying at room temperature. The morphology was evaluated by scanning electron microscopy (SEM) with an FE-SEM FEI Nova NanoSEM 230 microscope with vCD detector using chromium coating.

\section{Conclusions}

The synthesis conditions of mesoporous silica (SBA-15) and organosilica (PMO) molecular sieves could be adjusted using Pluronic P104 to yield hexagonal platelet-like particle morphology, short path lengths with various pore sizes. The use of expanders such as 1, 3, 5-trimethylbenzene (TMB) yielded in the formation of vesicles in all the syntheses attempted, whereas P104 combined with 1 , 3, 5-triisopropylbenzene (TIPB) resulted both in expanded E-SBA-15 and E-PMO with $12.3 \mathrm{~nm}$ pore size short channel particles in both cases. The addition of small amount (5\%) titanocene dichloride in the synthesis gel under mild acidic conditions also allowed obtaining Ti-SBA and Ti-PMO with good structural, morphological and textural properties. Large-pore Ti-E-SBA-15 (15.5 nm) could be obtained combining TIPB and P104 in swollen micelles, via co-condensation of tetramethoxysilane with $5 \%$ of 
$\mathrm{Cp}_{2} \mathrm{TiCl}_{2}$ at low gelling temperature $\left(15^{\circ} \mathrm{C}\right)$. However, the same approach was not successful in the case of Ti-PMO that has not been expanded further without losing the structural ordering.

Author Contributions: Conceptualization, I.D.; methodology, Y.A. and I.D.; software, Y.A. and I.D.; validation, Y.A. and I.D.; formal analysis, Y.A.; investigation, Y.A., Y.C., and I.D.; resources, I.D.; data curation, Y.A. and I.D.; writing-original draft preparation, Y.A. and I.D.; writing—review and editing, Y.A.; Y.C., and I.D.; visualization, Y.A. and I.D.; supervision, I.D. and Y.C.; project administration, I.D.; funding acquisition, I.D. All authors have read and agreed to the published version of the manuscript.

Funding: This work has been funded by the Spanish Research Agency (AEI) and the European Regional Development Fund (FEDER) through the Project MAT2016-77496-R, and CSIC Project iCOOP+2016 COOPA20136 and CSIC Project number 2019AEP076.

Acknowledgments: We thank the Chemistry Department, Addis Ababa University, and BETAQUIMICA for their support. Y.A. also acknowledges Assosa University for financial support.

Conflicts of Interest: The authors declare no conflict of interest. The funders had no role in the design of the study; in the collection, analyses, or interpretation of data; in the writing of the manuscript, or in the decision to publish the results.

\section{References}

1. Kresge, C.T.; Leonowicz, M.E.; Roth, W.J.; Vartuli, J.C.; Beck, J.S. Ordered mesoporous molecular sieves synthesized by a liquid crystal template mechanism. Nature 1992, 359, 710-712. [CrossRef]

2. Zhao, D.; Huo, Q.; Feng, J.; Chmelka, B.F.; Stucky, G.D. Nonionic triblock and star diblock copolymer and oligomeric surfactant syntheses of highly ordered, hydrothermally stable, mesoporous silica structures. J. Am. Chem. Soc. 1998, 120, 6024-6036. [CrossRef]

3. Tüysüz, H.; Schüth, F. Ordered Mesoporous materials as catalysts. Adv. Catal. 2012, 55, 127-239.

4. Hartmann, M. Ordered mesoporous materials for bioadsorption and biocatalysis. Chem. Mater. 2005, 17, 4577-4593. [CrossRef]

5. Inagaki, S.; Guan, S.; Fukushima, Y.; Ohsuna, T.; Terasaki, O. Novel mesoporous materials with a uniform distribution of organic groups and inorganic oxide in their frameworks. J. Am. Chem. Soc. 1999, 21, 9611-9614. [CrossRef]

6. Wahab, M.A.; Beltramini, J.N. Recent advances in hybrid periodic mesostructured organosilica materials: Opportunities from fundamental to biomedical applications. RSC Adv. 2015, 5, 79129-79151. [CrossRef]

7. Linton, P.; Alfredsson, V. Growth and morphology of mesoporous SBA-15 particles. Chem. Mater. 2008, 20, 2878-2880. [CrossRef]

8. Cao, L.; Man, T.; Kruk, M. Synthesis of Ultra-Large-Pore SBA-15 Silica with two-dimensional hexagonal structure using triisopropylbenzene as micelle expander. Chem. Mater. 2009, 21, 1144-1153. [CrossRef]

9. Awoke, Y.; Chebude, Y.; Márquez-Álvarez, C.; Díaz, I. Solvent free epoxidation of vernonia oil using Ti-SBA-15 with tailor made particle morphology and pore size. Catal. Today 2020, 345, 190-200. [CrossRef]

10. Gascon, V.; Diaz, I.; Marquez-Alvarez, C.; Blanco, R.M. Mesoporous silicas with tunable morphology for the immobilization of laccase. Molecules 2014, 19, 7057-7071. [CrossRef]

11. Kruk, M. Access to ultralarge-pore ordered mesoporous materials through selection of surfactant/ swelling-agent micellar templates. Acc. Chem. Res. 2012, 45, 1678-1687. [CrossRef] [PubMed]

12. Linton, P.; Wennerstrom, H.; Alfredsson, V. Controlling particle morphology and size in the synthesis of mesoporous SBA-15 materials. Phys. Chem. Chem. Phys. 2010, 12, 3852-3858. [CrossRef] [PubMed]

13. Melero, J.A.; Arsuaga, J.M.; de Frutos, P.; Iglesias, J.; Sainz, J.; Blázquez, S. Direct synthesis of titanium-substituted mesostructured materials using non-ionic surfactants and titanocene dichloride. Microporous Mesoporous Mater. 2005, 86, 364-373. [CrossRef]

14. Thommes, M.; Kaneko, K.; Neimark, A.V.; Olivier, J.P.; Rodriguez-Reinoso, F.; Rouquerol, J.; Sing, K.S.W. Physisorption of gases, with special reference to the evaluation of surface area and pore size distribution (IUPAC Technical Report). Pure Appl. Chem. 2015, 87, 1051-1069. [CrossRef]

15. Nguyen, T.P.B.; Lee, J.-W.; Shim, W.G.; Moon, H. Synthesis of functionalized SBA-15 with ordered large pore size and its adsorption properties of BSA. Microporous Mesoporous Mater. 2008, 110, 560-569. [CrossRef]

16. Yao, Y.; Feng, J.; Han, L.; Che, S. Hierarchal multi-lamellar silica vesicle clusters synthesized through self-assembly and mineralization. RSC Adv. 2015, 5, 102256-102260. [CrossRef] 
17. Yuan, P.; Yang, S.; Wang, H.; Yu, M.; Zhou, X.; Lu, G.; Zou, J.; Yu, C. Structure transition from hexagonal mesostructured rodlike silica to multilamellar vesicles. Langmuir 2008, 24, 5038-5043. [CrossRef]

18. Zhang, W.-H.; Lu, J.; Han, B.; Li, M.; Xiu, J.; Ying, P.; Li, C. Direct synthesis and characterization of titanium-substituted mesoporous molecular sieve SBA-15. Chem. Mater. 2002, 14, 3413-3421. [CrossRef]

19. Melero, J.A.; Iglesias, J.; Arsuaga, J.M.; Sainz-Pardo, J.; de Frutos, P.; Blazquez, S. Synthesis and catalytic activity of organic-inorganic hybrid Ti-SBA-15 materials. J. Mater. Chem. 2007, 17, 377-385. [CrossRef]

20. Guo, W.; Zhao, X.S. Room-temperature synthesis of hydrothermally stable aluminum-rich periodic mesoporous organosilicas with wormlike pore channels. Microporous Mesoporous Mater. 2005, 85, 32-38. [CrossRef]

21. Johansson, E.M.; Córdoba, J.M.; Odén, M. The effects on pore size and particle morphology of heptane additions to the synthesis of mesoporous silica SBA-15. Microporous Mesoporous Mater. 2010, 133, 66-74. [CrossRef]

22. Van der Voort, P.; Esquivel, D.; De Canck, E.; Goethals, F.; Van Driessche, I.; Romero-Salguero, F.J. Periodic mesoporous organosilicas: From simple to complex bridges; a comprehensive overview of functions, morphologies and applications. Chem. Soc. Rev. 2013, 42, 3913-3955. [CrossRef] [PubMed]

23. Bao, X.Y.; Zhao, X.S.; Qiao, S.Z.; Bhatia, S.K. Comparative analysis of structural and morphological properties of large-pore periodic mesoporous organosilicas and pure silicas. J. Phys. Chem. B 2004, 108, 16441-16450. [CrossRef]

Sample Availability: Samples of the compounds are available from the authors.

Publisher's Note: MDPI stays neutral with regard to jurisdictional claims in published maps and institutional affiliations.

(C) 2020 by the authors. Licensee MDPI, Basel, Switzerland. This article is an open access article distributed under the terms and conditions of the Creative Commons Attribution (CC BY) license (http://creativecommons.org/licenses/by/4.0/). 